\title{
The Issue of Recycling Waste from the Oil Refining Industry for Use in the Production of Rubber Products
}

\author{
Zharylkasyn P.M., Ramatullaeva L.I., Kenzhalieva G.D., Kocherov E.N., Shapalov Sh.K., Kerimbekova Z.M. \\ M. Auezov South Kazakhstan State University, Tauke Khan av.5, 160001, Shymkent, Kazakhstan.
}

ORCID: 0000-0002-3828-0154 (Zharylkasyn P.M.)

\begin{abstract}
The article describes additional secondary semi-finished products, or sulfur-based waste, that occur as a result of the oil production and processing industry, which is the main economic sector of the country. Literary and practical representation of their huge volume on the occupied territory, negative impact on the environment, flora, fauna and local residents. It is scientifically detailed that enterprises of this industry, storing sulfur waste in open areas, bring irreplaceable losses of human life. As one of the main raw materials in the production of waste from oil production and processing - sulfur rubber products, the ways of their utilization have been studied. The results of the study of sulfur samples using modern physical-chemical and electronmicroscopic methods have shown its application. Studies of serial formulations of rubber mixtures for tire tread and filling cord of light tires of sulfur tenza were conducted. The results of the study of the influence of residual sulfur on the physicalchemical and technical-operational properties of the Breker and tread Rubbers are presented.The basis of research on the development of technology for obtaining composite materials using waste oil production-sulfur and environmental impact assessment for open storage of lump sulfur-waste oil production, ensuring the safety of professional and technological equipment, the results of theoretical and practical research on production.
\end{abstract}

Keywords: Oil production, Sulfur residue, Environment, Life safety, Rubber, Technology.

\section{INTRODUCTION}

In the North Caspian region of oil production, Kazakhstan together with foreign companies is implementing a number of promising and large-scale projects. Marine crude oil and other deposits in this region are high-grade, that is, the most important feature of this oil is the high content of hydrogen sulfide in the associated gas. To deliver crude oil to marketable condition, it is refined and as a result, elemental sulfur is obtained. Along with the increase in oil production, the accumulation of sulfur is also increasing. By 2018, 9.2 million cubic meters of sulfur will be created in the storage of sulfur emissions from the Tengiz field in the zhylyoy district of Atyrau region, which is formed as a result of oil processing directly in the open air. the volume reserve of tons has been accumulated.
It should be noted that issues related to the storage of sulfur, which belongs to the IV hazard class, are still relevant today. This can lead to inflammation of the mucous membrane of the eyes and upper respiratory tract, skin irritation, diseases of the gastrointestinal tract, as well as the maintenance, accumulation and storage of sulfur in an open environment, which negatively affects the environment and human life [1].

The composition of oil and associated gases of marine oil contains about $14 \%$ of hydrogen sulfide. Hydrogen sulfide released by separation from oil supplied to the production site by associated gases is broken down into water and sulfur at the Claus plant. The extracted liquid sulfur is sent to granulation or to tanks or to storage of sulfur-containing waste. Lump sulfur is sulfur stored as blocks in waste storage facilities [2].

Today, oil and gas processing enterprises in the world annually account for about 50 million us dollars.the production of about a ton of sulfur. Only in the country, the Tengiz gas and oil refinery allocated 1 million us dollars per year as a result of primary oil purification from associated components. more than a ton of sulfur is produced [3].

Environmental pollution is increasing due to the widespread introduction of energy-intensive and chemical technologies, the production of new chemical products, the increase in international sales of chemicals and technologies, and insufficient environmental control in almost all areas of human activity [4].

Several methods of desulphurization of oil and petroleum products are known [5]. Outdated technologies of oil desulphurization and irrational use of secondary products have a negative impact on the ecological state of the country's natural environment. In this regard, the development and implementation of waste-free, low-waste and high-efficiency technologies is particularly relevant and promising. The technology of heat-resistant composite materials to be processed must comply with the rules "sanitary and epidemiological requirements for establishing a sanitary protection zone of production facilities" [6] and "Environmental code of the Republic of Kazakhstan" [7].

Sulfur is a volcanic agent for many rubber products, including tires. Continuously increasing requirements for the quality of tires require the creation of effective components of rubber mixtures. Special attention is paid to the improvement of vulcanizing agents [8]. 
Sulfur is the main volcanic agent for many composite compounds based on synthetic rubbers, including rubber technical products. A special requirement for its quality and chemical composition is made: the degree of purity and a high degree of dispersion of the product. These characteristics determine the vulcanization activity of sulfur, its dispersion in rubber, technological and technical properties of rubber and rubber mixtures. Polymer sulfur allows you to reduce the amount of sulfur in the process, without reducing the speed of vulcanization, which leads to an increase in the quality of the rubber. The use of polymer sulfur allows you to regulate the elastic properties of the produced rubber [9].

Based on a preliminary study of physico-chemical properties of the waste oil production and refining and activation of dispersive properties in a given direction, new technology for producing heat-resistant composites associated with the consumption of tenge sulfur provides improved technical and economic indicators of work of oil and petrochemical industry, i.e., is of great economic, social and environmental value. [10].

\section{MATERIALS AND METHODS}

Waste from oil production and refining-sulfur is a vulcanizing agent for many rubber products, including tires. Its quality and chemical composition are subject to special requirements, which primarily include a high degree of product purity (variable valence mixture-minimum metal content) and a high degree of dispersion. These characteristics determine the vulcanization activity of sulfur, its distribution in rubber, technological and technical properties of rubber mixtures and rubber [11].

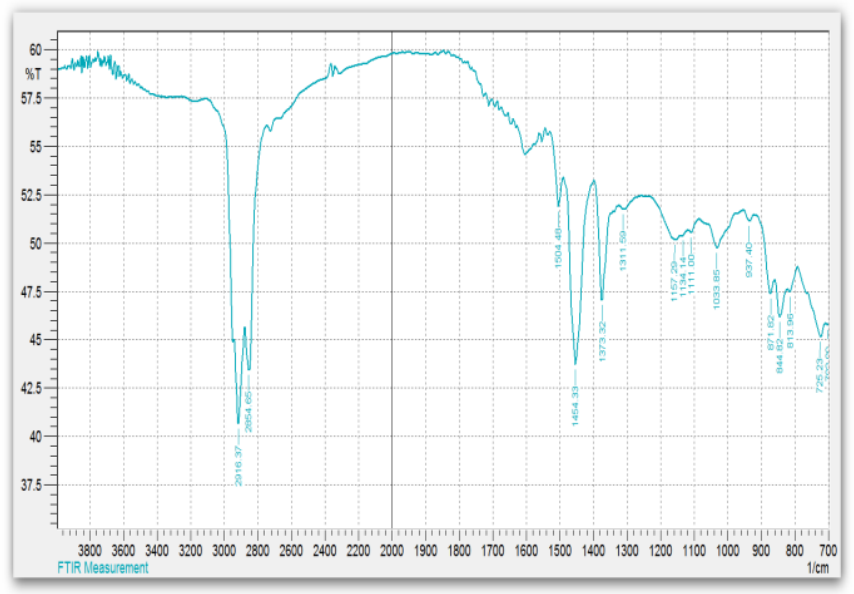

Fig.1. X-ray of shadow sulfur

According to the results of the analysis, the chemical composition of residual oil production - lump sulfur was determined. It was established that sea sulfur has the following chemical composition, mol\%: S -98.61; Mg-0.001; Al-0.001; Cu-0.0005; Fe-0.005.

The research presents the results of experiments on the possibility of using polymeric sulfur from oil refining waste.
Polymeric sulfur can reduce the amount of sulfur in the formulation without reducing the rate of vulcanization, which leads to an increase in the quality of the rubber. Allows you to adjust the elastic properties of the rubber obtained as a result of the use of polymer sulfur. Sea sulfur, which contains many impurities, was purified and polymerized. Polymeric sulfur is obtained from the melt by sudden cooling of molten sulfur in a hardened medium. Polymeric sulfur was obtained in the form of a light yellow dispersed powder.

Electron microscopic studies were performed to further study the mineralogical and structural features of sulfur samples (Fig. 2).
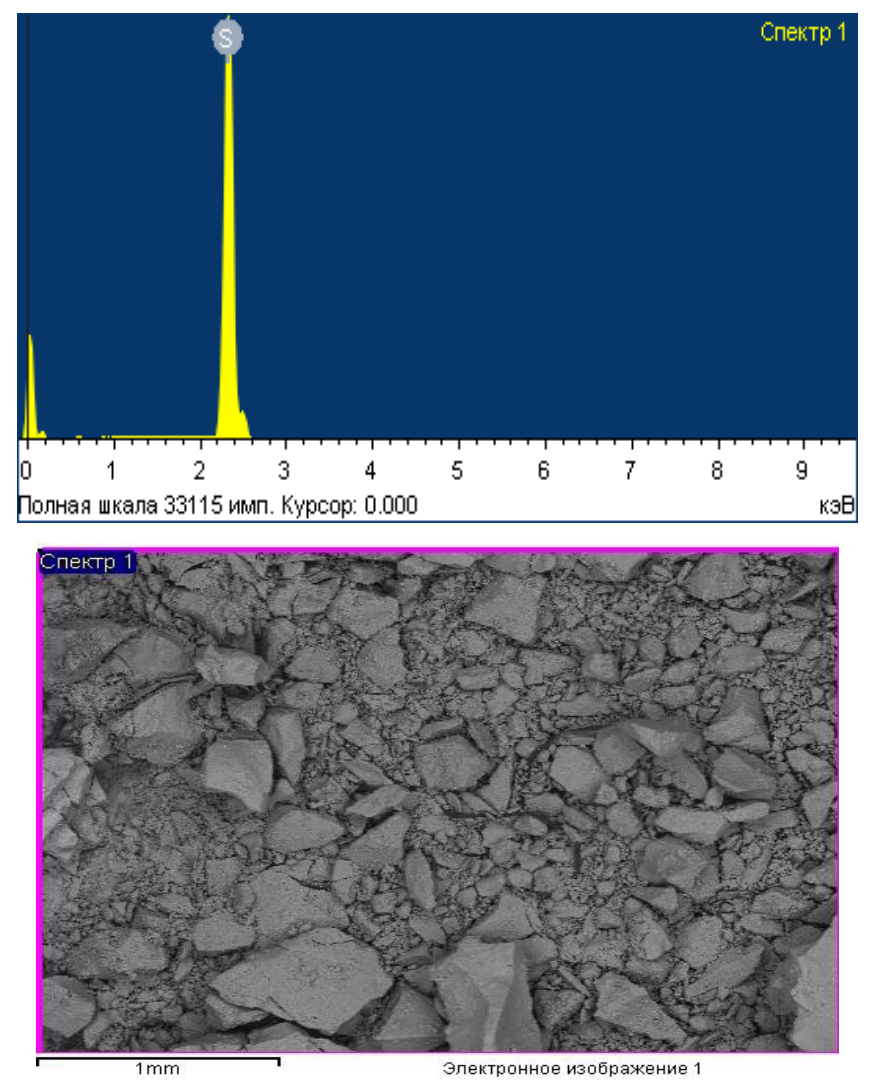

Fig.2. electronic microniser sulfur framework and the results of energy dispersive microanalysis

The SEM drawing of the sample shows individual parts in the form of aggregates of 10-15 microns in size. As can be seen in figure 2 , the descriptive presence of sulfur of the type under study occurs. Here, sulfur contributes to the development of effective softening indicators in the system, having moisturizing cassettes.

\section{RESULTS AND DISCUSSION}

Studies were conducted in serial formulations of rubber mixtures for the filling cord of light tires and tire tread with different amounts of shadow sulfur. Recipes for rubber mixtures are given in tables 1 and 2 . 
International Journal of Engineering Research and Technology. ISSN 0974-3154, Volume 13, Number 6 (2020), pp. 1210-1214

(C) International Research Publication House. https://dx.doi.org/10.37624/IJERT/13.6.2020.1210-1214

Table 1. formulations of the studied rubber mixtures for the filling cord of light tires

\begin{tabular}{|l|c|c|c|c|c|c|c|}
\hline \multirow{2}{*}{ Ingredients name } & \multicolumn{7}{|c|}{100 mass of rubber. parts } \\
\cline { 2 - 8 } & Control version & $\begin{array}{c}1 \\
\text { version }\end{array}$ & $\begin{array}{c}2 \\
\text { version }\end{array}$ & $\begin{array}{c}3 \\
\text { version }\end{array}$ & $\begin{array}{c}4 \\
\text { version }\end{array}$ & $\begin{array}{c}5 \\
\text { version }\end{array}$ & $\begin{array}{c}6 \\
\text { version }\end{array}$ \\
\hline SCR-3 & 80,0 & 80,0 & 80,0 & 80,0 & 80,0 & 80,0 & 80,0 \\
\hline BMSR -30 SRBM -15 & 20,0 & 20,0 & 20,0 & 20,0 & 20,0 & 20,0 & 20,0 \\
\hline Technical sulfur & 2,20 & 2,20 & 2,20 & 2,20 & 2,20 & 2,20 & 2,20 \\
\hline Sea sulfur & 2,00 & 0,5 & 1,0 & 1,5 & 2,0 & 2,5 & 3,0 \\
\hline Sulfenamide M & 1,40 & 1,40 & 1,40 & 1,40 & 1,40 & 1,40 & 1,40 \\
\hline Santogard PVI & 0,30 & 0,30 & 0,30 & 0,30 & 0,30 & 0,30 & 0,30 \\
\hline RU modifiers & 1,00 & 1,00 & 1,00 & 1,00 & 1,00 & 1,00 & 1,00 \\
\hline Gepsol CIS & 0,50 & 0,50 & 0,50 & 0,50 & 0,50 & 0,50 & 0,50 \\
\hline Zinc belt & 7,00 & 7,00 & 7,00 & 7,00 & 7,00 & 7,00 & 7,00 \\
\hline APER & 10,00 & 10,00 & 10,00 & 10,00 & 10,00 & 10,00 & 10,00 \\
\hline Pine rosin & 4,00 & 4,00 & 4,00 & 4,00 & 4,00 & 4,00 & 4,00 \\
\hline Hydrocarbon resins & 3,00 & 3,00 & 3,00 & 3,00 & 3,00 & 3,00 & 3,00 \\
\hline Stearic acid & 3,00 & 3,00 & 3,00 & 3,00 & 3,00 & 3,00 & 3,00 \\
\hline PP-6SH & 6,0 & 6,0 & 6,0 & 6,0 & 6,0 & 6,0 & 6,0 \\
\hline Antioxidant, Diafen FP & 0,50 & 0,50 & 0,50 & 0,50 & 0,50 & 0,50 & 0,50 \\
\hline Natural boron & 20,00 & 20,00 & 20,00 & 20,00 & 20,00 & 20,00 & 20,00 \\
\hline Kaolin & 20,00 & 20,00 & 20,00 & 20,00 & 20,00 & 20,00 & 20,00 \\
\hline Technical carbon P514 & 40,00 & 40,00 & 40,00 & 40,00 & 40,00 & 40,00 & 40,00 \\
\hline Technical carbon P514 & 35,00 & 35,00 & 35,00 & 35,00 & 35,00 & 35,00 & 35,00 \\
\hline
\end{tabular}

Mixing of rubber mixtures was carried out in laboratory rollers PD 630315/315. The duration of the intervention is the same in all cases-20 minutes. There were no difficulties during the mixing process.

Table 2. formulations of the studied rubber compounds for tire tread

\begin{tabular}{|l|c|c|c|c|c|}
\hline \multirow{2}{*}{ Ingredients name } & \multicolumn{5}{|c|}{100 mass of rubber. parts } \\
\cline { 2 - 6 } & $\begin{array}{c}\text { control } \\
\text { version }\end{array}$ & $\begin{array}{c}1 \\
\text { version }\end{array}$ & $\begin{array}{c}2 \\
\text { version }\end{array}$ & $\begin{array}{c}3 \\
\text { version }\end{array}$ & $\begin{array}{c}4 \\
\text { version }\end{array}$ \\
\hline BMSR -30 SRBM -15 & 100,0 & 100,0 & 100,0 & 100,0 & 100,0 \\
\hline Sulfur & 1,9 & 1,3 & 1,5 & 1,7 & 1,9 \\
\hline "C" sulfenamide & 1,4 & 1,4 & 1,4 & 1,4 & 1,4 \\
\hline Santogard PVI & 0,3 & 0,3 & 0,3 & 0,3 & 0,3 \\
\hline Zinc white & 3,0 & 3,0 & 3,0 & 3,0 & 3,0 \\
\hline Stearic acid & 2,0 & 2,0 & 2,0 & 2,0 & 2,0 \\
\hline $\begin{array}{l}\text { Alkylethanolamines } \\
\text { resin }\end{array}$ & 2,0 & 2,0 & 2,0 & 2,0 & 2,0 \\
\hline Hydrocarbon resins & 4,0 & 4,0 & 4,0 & 4,0 & 4,0 \\
\hline Plasticizer oil PN-6SH & 3,0 & 3,0 & 3,0 & 3,0 & 3,0 \\
\hline Protective wax EVP & 1,0 & 1,0 & 1,0 & 1,0 & 1,0 \\
\hline Diafen FP & 1,5 & 1,5 & 1,5 & 1,5 & 1,5 \\
\hline Acetononil R, RS & 1,0 & 1,0 & 1,0 & 1,0 & 1,0 \\
\hline Carbon black P-245 & 60,0 & 60,0 & 60,0 & 60,0 & 60,0 \\
\hline
\end{tabular}

Physical and mechanical properties of vulcanizates based on General-purpose rubbers for the manufacture of filling cords for light tires with polymer sulfur are shown in table 3 .

Table 3. properties of vulcanizates for the manufacture of filling cord of light tires

\begin{tabular}{|c|c|c|c|c|c|c|c|}
\hline $\begin{array}{c}\text { Indicators } \\
\text { name }\end{array}$ & Reference & $\begin{array}{c}1 \\
\text { version }\end{array}$ & $\begin{array}{c}2 \\
\text { version }\end{array}$ & $\begin{array}{c}3 \\
\text { version }\end{array}$ & $\begin{array}{c}4 \\
\text { version }\end{array}$ & $\begin{array}{c}5 \\
\text { version }\end{array}$ & $\begin{array}{c}6 \\
\text { version }\end{array}$ \\
\hline $\begin{array}{c}\text { Conditional } \\
\text { tensile } \\
\text { strength, } \\
\text { MPa, not } \\
\text { less }\end{array}$ & 12,0 & 11,2 & 11,2 & 11,8 & 12,1 & 12,1 & 11,8 \\
\hline $\begin{array}{c}\text { Rated } \\
\text { voltage at } \\
300 \% \\
\text { elongation, } \\
\text { MPa }\end{array}$ & 7,1 & 7,1 & 7,2 & 7,2 & 7,4 & 7,3 & 7,3 \\
\hline $\begin{array}{c}\text { Elongation } \\
\text { at break\%, } \\
\text { not less }\end{array}$ & 480 & 482 & 482 & 495 & 505 & 507 & 497 \\
\hline $\begin{array}{c}\text { Shore a } \\
\text { hardness, } \\
\text { standard } \\
\text { unit }\end{array}$ & 77 & 76 & 78 & 78 & 78,5 & 78 & 75 \\
\hline
\end{tabular}


Physical and mechanical properties of tread rubber are shown in table 4.

Table 4. physical and mechanical properties of tread rubber

\begin{tabular}{|l|c|c|c|c|c|}
\hline \multirow{2}{*}{ Indicators } & \multirow{2}{*}{$\begin{array}{c}\text { Reference } \\
\text { additive }\end{array}$} & \multicolumn{4}{|c|}{ mixture under study } \\
\cline { 3 - 6 } & 11,8 & 11,5 & 11,7 & 1,9 \\
\hline $\begin{array}{l}\text { Rated voltage at 300\% } \\
\text { elongation, MPa }\end{array}$ & 11,7 & 11,6 \\
\hline $\begin{array}{l}\text { Conditional tensile } \\
\text { strength, MPa }\end{array}$ & 17,55 & 17,1 & 17,60 & 17,50 & 17,40 \\
\hline $\begin{array}{l}\text { Elongation of the ratio } \\
\text { at break, \% }\end{array}$ & 530 & 510 & 530 & 500 & 490 \\
\hline $\begin{array}{l}\text { Obstacles to breakage, } \\
\text { kN/m }\end{array}$ & 54 & 53 & 57 & 55 & 55 \\
\hline $\begin{array}{l}\text { Shore hardness, } \\
\text { conditional.ed. }\end{array}$ & 65 & 60 & 67 & 66 & 64 \\
\hline
\end{tabular}

Polymer sulfur is introduced into the rubber mixture to completely or partially replace technical sulfur.

The samples were vulcanized at a temperature of $155^{\circ} \mathrm{C}$ for 15 minutes. Wear tests of samples were carried out in an autoclave for 40 hours in a saturated water vapor environment at a pressure of $0.2 \mathrm{MPa}$ at a temperature of $393^{\circ} \mathrm{C}$, and for 14 hours under constant humidification with a $5 \%$ aqueous solution of $\mathrm{NaCl}$.

Table 5. Physical and mechanical properties of tread rubber

\begin{tabular}{|c|c|c|c|c|c|}
\hline \multirow{2}{*}{ Indicators } & \multicolumn{5}{|c|}{$\begin{array}{l}100 \text { mass of rubber. part } \\
\text { the content of polymeric } \\
\text { sulfur }\end{array}$} \\
\cline { 2 - 7 } & reference & 0,5 & 1,0 & 1,3 & 1,5 \\
\hline $\begin{array}{c}\text { Tension at 300\% elongation, } \\
\text { MPa }\end{array}$ & 8,5 & 8,9 & 8,7 & 8,6 & 8,5 \\
\hline $\begin{array}{c}\text { Conditional tensile strength, } \\
\text { MPa }\end{array}$ & 20,0 & 19,9 & 20,7 & 20,8 & 21,2 \\
\hline Elongation at break, \% & 650 & 650 & 643 & 644 & 645 \\
\hline Plowing resistance, kN/m & 70 & 72 & 68 & 68 & 75 \\
\hline $\begin{array}{c}\text { When stretching several reets, } \\
\text { the tensile resistance is 200\%, } \\
\text { thousand. cycle }\end{array}$ & 4,2 & 3,05 & 5,5 & 5,6 & 4,8 \\
\hline Fatigue, $\mathrm{kJ} / \mathrm{m} 3$ & 45 & 48 & 45,7 & 45,9 & 44,5 \\
\hline $\begin{array}{c}\text { The shore hardness, } \\
\text { conditional unit }\end{array}$ & 52 & 53 & 53 & 53 & 55 \\
\hline
\end{tabular}

For partial or complete replacement of conventional sulfur in a rubber mixture of sulfur obtained from oil refining waste. During the practice, tread and Brecker rubber mixtures were used.The mixtures were made in two stages, and the sulfur obtained during oil refining was introduced in laboratory rollers.

The technology of mixing, processing and vulcanization of rubber mixtures practically did not differ from the standard mode specified in the technological regulations. The samples were vulcanized at a temperature of $155^{\circ} \mathrm{C}$ for 15 minutes. Wear tests of samples were performed in an autoclave for 40 hours in a saturated water vapor environment at a pressure of $0.2 \mathrm{MPa}$ at a temperature of $393^{\circ} \mathrm{C}$, and for 8 hours under constant humidification with $5 \% \mathrm{NaCl}$ water solution.

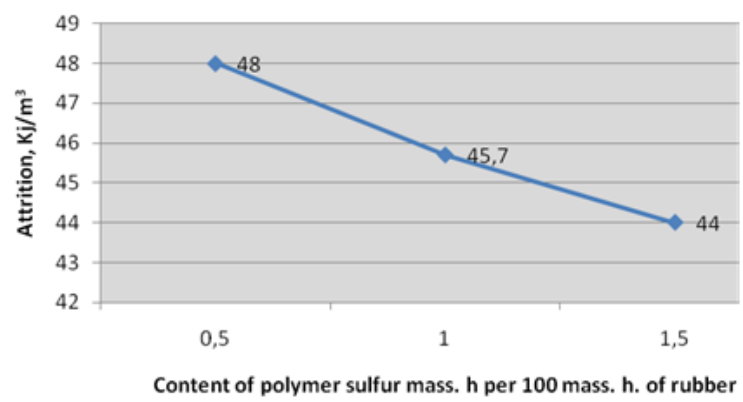

Fig.3. dependence of physical and chemical properties of tread rubber on the amount of sulfur

As shown in figure 4, an increase in the relative tensile strength of tread rubber when using purified shadow sulfur and a decrease in viscosity prove an improvement in strength.

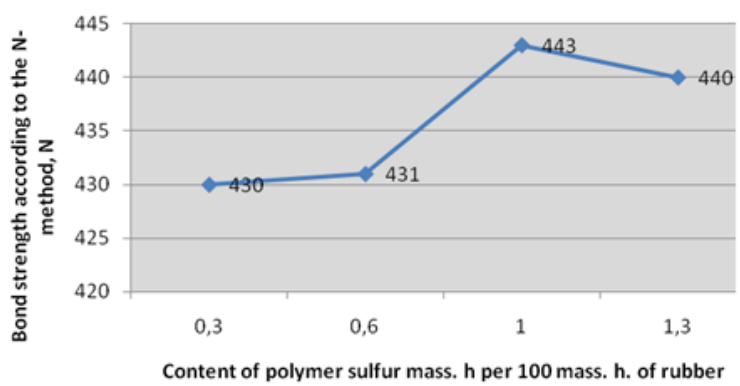

Fig.4. influence of sulfur content on physical and chemical properties of Brecker Rubbers

Methods of physical, chemical, physical and mechanical analysis and methods of technical and operational testing were used in the work.

Electron-microscopic examination and X-ray-energy dispersion microanalysis of raw materials and samples of products based on them in the Regional Laboratory of Engineering Profile "Structural and Biochemical Materials" M. Auezov SKSU.

Physical and chemical analysis of raw materials was carried out in the specialized laboratory of physical and chemical analysis methods "Quality".

Technical and operational test methods were specially performed in the "Comprehensive Laboratory of Modern Test Methods" S. Auezov SKSU.

In figure 5, there is a significant increase in the strength of the Brecker rubber, characterized by a conditional tensile strength and the strength of the bond between the rubber and the textile stock. 
The positive influence of polymer sulfur on the technological properties of the studied rubber mixtures was established. Polymer sulfur was easily introduced into the rubber mixture. The distribution of polymer sulfur in rubber is satisfactory, which does not require changing the order of rolling and vulcanization.

As can be seen from table 3, the content of polymer sulfur in comparison with standard samples is 2-2.5 wt. b.the conditional tensile strength, if present, has the maximum values. The polymer sulfur content of $3.0 \mathrm{wt}$.promotion to $\mathrm{b}$. will lead to the decrease of this indicator of strength. The content of polymer sulfur with an elongation of the values of the conditional voltage by $300 \%$ and the shore stiffness-2- 2 . 5 wt. B. is optimal in the presence of. A further increase in the amount of polymer sulfur will reduce the stiffness from 78.5 to 75 conventional units.

If we talk about the data in tables 4 , the test results contain polymer sulfur in rubbers of $1.5 \mathrm{wt}$.at the same time, he showed that the physical and mechanical properties have a better complex.

According to the results of the studies indicated in table 5, the most optimal amount of polymer sulfur that reaches the maximum basic physical and mechanical properties of tread rubber is 100 mass of rubber. 3 mass. 2) part. The dosage of technical sulfur in the reference recipe in this order is 100 mass of rubber. 0.5 times more consumption of polymer sulfur. This appears to be fully involved in the vulcanization reaction as a result of polymer sulfur activity, while forming very strong Sulfur bubbles, from which a partial increase in the strength of vulcanizates occurs in small amounts in clays.

\section{CONCLUSION}

Formulations of composite materials containing tengue sulfur were developed, technological and physical and mechanical tests were conducted to determine the quality of the resulting composite materials-technical rubber.

The influence of shadow sulfur on the vulcanization time and rubber properties was studied. The dependence of shadow sulfur concentration on the quality of composite materials is established.

The optimal rate of shadow sulfur is 100 wt. b. rubber 3.5 wt.b. the formula of fillers is defined.

The use of sulfur tena leads to increased heat resistance, including rubber cord filler, due to the increasing number of intermolecular bonds in the elastomeric matrix in connection with the reaction of sulfur in the recipe.

The technology of manufacturing rubber compounds and their vulcanization is provided. It is established that the filling elastic band - the quality of the obtained composite materials meets the requirements of GOST 263-85 and the standards of technological regulations. Recommended formulations of filling cords save a large resource of the outer rubber of the car.

\section{REFERENCES}

[1] Babin M.S. The ecological mechanism of nature management and environmental protection. - M: Infa. - M, 203 p. 2001.

[2] Podvalov Yu.A. Ecology of oil and gas production. M .: Infra-Engineering, 2010 . $416 \mathrm{p}$.

[3] Zharylkasyn P.M., Bagova Z.I., Turebekova G.Z. Environmental impact of Tengiz sulfur as a result of open storage. Proceedings of the "International Scientific and Practical Conference" Auezov Readings - 14: the innovative potential of science and education in Kazakhstan in the new global reality ". Shymkent, April 2016, p. 247-250.

[4] Order of the Minister of Environmental Protection of the Republic of Kazakhstan dated June 28, 2007 No. 204-p "On approval of the Instructions for assessing the impact of planned economic and other activities on the environment in the development of pre-planned, planned, pre-project and project documentation".

[5] Sanitary rules "Sanitary and epidemiological requirements for the establishment of a sanitary protection zone of production facilities" (approved by order of the Minister of National Economy of the Republic of Kazakhstan dated March 20, 2015 No. 237).

[6] "Environmental Code of the Republic of Kazakhstan" Code of the Republic of Kazakhstan dated January 9, 2007 No. 212-III.

[7] The concept of environmental safety of the Republic of Kazakhstan, Astana, Nature Protection. Atmosphere. Determination of emission parameters of lead, zinc, copper and compounds, STRK 10522002, Astana, 2003. 68p.

[8] Zharylkasyn P.M., Bagova Z.I. et al. Ways to utilize sulfur - waste oil from the Tengiz field. Science, education and innovation are factors in the implementation of the Kazakhstan-2050 strategy. Collection of materials of the International XV Baikonur Readings. Zhezkazgan, December 2015, pp. 371-373.

[9] Smirnova V.I. Ecology and industry. - M: Nedra, 2005, 211 p.

[10] Kenzhegaliev A. Ecological condition of the Tengiz field and the ways of its recovery. Oil and gas of Kazakhstan. 1997, No. 2. S.119-122.

[11] Turebekova G.Z., Naukenova A.S. and others. Opportunities for the utilization of sulfur-waste from the oil refining industry through application in technical rubbers. Bulletin of the National Academy of Sciences of the Republic of Kazakhstan. Volume 1. No. 359 (2016). - pp. 10-15. 